\title{
"Por volta da hora sexta" (Jo 19,14): Os seis sinais e a hora de Jesus no Quarto Evangelho
}

\author{
"About the sixth hour" (Joh 19, 14): \\ The six signs and the hour of Jesus in the \\ Fourth Gospel
}

Luís Henrique Eloy e Silva

\section{Resumo}

O escopo dos sinais, conforme narrado em Jo 20,30-31, é o de suscitar a fé em Jesus, o Cristo, o Filho de Deus, e em seu nome ter a vida. Sinal, fé, cristologia e soteriologia interligam-se em sua compreensão hermenêutica. Os autores não são concordes quanto ao número dos sinais. Seriam eles sete, o número da completude e perfeição, ou seis? O presente estudo visa levantar uma vez mais tal discussão, em busca de um novo horizonte hermenêutico.

Palavras-chave: Evangelho de João. Sinais. Cristologia. Soteriologia.

\begin{abstract}
The scope of the signs, as narrated in Joh 20,30-31, is to arouse faith in Jesus, the Christ, the Son of God, and to have life in his name. Sign, faith, christology and soteriology are intertwined in their hermeneutic understanding. The authors do not agree on the number of signs. Was it seven, the number of completeness and perfection, or six? The present study aims to raise such discussion once again, in search of a new hermeneutic horizon.
\end{abstract}

Keywords: Gospel of John. Signs. Christology. Soteriology. 


\section{Introdução}

A contagem do número dos sinais realizados por Jesus no quarto evangelho e seu consequente significado tem sido há muito uma quaestio disputata entre os autores. Enquanto alguns defendem que o número dos sinais seria sete, partindo do simbolismo bíblico desse número como indicador da perfeição dos sinais no evangelho, ${ }^{1}$ outros pensam que o número deva ser seis. ${ }^{2}$

Nessa perspectiva, os sinais comumente elencados seriam os seguintes: ${ }^{3}$

1. A mudança da água em vinho nas Bodas de Caná (Jo 2,1-12);

2. A cura do filho do funcionário régio em Caná (Jo 4,46-54);

3. A cura do paralítico na piscina de Betzata (5,1-15);

4. A multiplicação dos pães na Galileia (Jo 6,1-15);

5. O caminhar de Jesus sobre as águas do mar da Galileia (Jo 6,16-21);

6. A cura do cego de nascença em Jerusalém (Jo 9,1-41);

7. A ressureição de Lázaro em Betânia (Jo 11,1-54).

A diferença fundamental, para quem discorda do número sete, é que o texto de Jo 6,16-21 não deveria ser contado no catálogo.

As diferenças, entretanto, podem tornar-se mais complexas quando os vários autores sugerem a inclusão de outras passagens do evangelho como possíveis sinais, ${ }^{4}$ ou o mistério da hora de Jesus como o sinal por excelência ao qual todos os outros precedentes, no curso da narrativa, aludiriam. Sob

\footnotetext{
${ }^{1}$ DODD, C. H., The Interpretation of the Fourth Gospel, p. 438; FORTNA, R. T., The Gospel of Signs, p. 100-101; SMALLEY, S. S., John, p. 86-87; MORRIS, L., Jesus is the Christ, p. 21; BROWN, R. E., An Introduction do the Gospel of John, p. 300.

${ }^{2}$ SANDERS, J. N., A Commentary on the Gospel According to St. John, p. 5.

${ }^{3}$ BROWN, R. E., An Introduction do the Gospel of John, p. 300.

${ }^{4}$ Fortna defende que a multiplicação dos pães e o caminhar de Jesus sobre as águas em Jo 6,1-21 seria um único sinal e acrescenta a pesca de Jo 21 como o sétimo sinal: FORTNA, R. T., The Gospel of Signs, p. 100-101. BEASLEY- MURRAY, G. R., John, p. 42 e CARSON D. A., The Gospel According to John, p. 181 sustentam que a purificação do templo em Jo 2,14-17 deva ser incluída. A fala de Jesus sobre a serpente no deserto (Jo 3,14-15) também é considerada um sinal segundo BROWN, R. E., The Gospel According to John I-XII, p. 528. Dodd, por sua vez, inclui a unção de Jesus por Maria em Jo 12,1-8 e a entrada triunfal em Jo 12,12-16: DODD C. H., The Interpretation of the Fourth Gospel, p. 438. Semelhantemente, sustentam BULTMANN, R., Theologie des Neuen Testaments, p. 409-410 e BEASLEY-MURRAY, G. R., John, p. 387 que também devam ser incluídas as aparições do ressuscitado em Jo 20-21.
} 
esta ótica, o grande sinal seria a morte, ressurreição e exaltação de Cristo. ${ }^{5}$

Neste artigo, buscar-se-á, em base a critérios da análise narrativa e da teologia que dela decorre, em consonância com um elemento simbólico sutilmente delineado nas páginas do quarto evangelho, não em oposição frontal aos que diversamente de nós pensam, mas pelo contrário, como demonstraremos, em respeitoso diálogo com o resultado de suas pesquisas e, paradoxalmente, em linha de reflexão epistemológica continuativa com muitas dessas pesquisas, demonstrar que, na balança hermenêutica do curso da reflexão, o número seis dos sinais parece manter seu peso maior.

\section{Os sinais em sua dimensão hermenêutica}

Em Jo 20,30-31 é dada ao leitor ${ }^{6}$ a finalidade pela qual os sinais foram postos por escrito:

Jesus fez ainda, diante de seus discípulos, muitos outros sinais, que não se acham escritos neste livro.

Esses, porém, foram escritos para que acrediteis que Jesus é o Cristo, o Filho de Deus, e para que, crendo, tenhais vida em seu nome.

O v. 30 nos fala dos muitos sinais que Jesus realizou e os quais não se encontram no evangelho. O v. 31 faz uma restrição afirmando que "esses" foram escritos com uma dupla finalidade, como nos indicam as duas orações subordinadas adverbiais finais no v. 31: para que acrediteis que Jesus é o Cristo, o Filho de Deus e para que tenhais vida em seu nome.

$\mathrm{Na}$ primeira subordinada final, o evangelista indica que Jesus de Nazaré não pode ser compreendido separadamente de seu aspecto messiânico, ou seja, ele é o Messias, o ungido, mas indica ainda que a messianidade de

\footnotetext{
${ }^{5}$ DODD, C. H., The Interpretation of the Fourth Gospel, p. 379; THÜSING, W., Die Erhöhung und Verherrlichung Jesu im Johannesevangelium, p. 289; BETZ, O., Jesus, p. 412-413. No dizer de NICOL, W., The Semeia in the Fourth Gospel, p. 115: "John never directly says the resurrection is also a semeion, but it is significant that when the Jews ask Jesus for a semeion in $2: 18$, he answers by referring to his resurrection". Carson, por sua vez, sustenta: "the greatest sign of them all is the death, resurrection and exaltation of the incarnate Word": CARSON, D. A., The Gospel According to John, p. 661.

${ }^{6}$ A expressão "o leitor" aqui refere-se ao conceito da análise narrativa "leitor implícito" cunhado por Wolfgang Iser em sua obra: Der Implizite Leser.
} 
Jesus não pode ser compreendida sem a sua filiação divina, ele é o Filho de Deus. Numa forma esquemática se vê como há uma restrição progressiva: Jesus é o Cristo, o Cristo é o Filho de Deus. Filho, último título dessa tríplice cadeia, é o conceito fundamental para expressar a identidade de Jesus n o quarto evangelho. ${ }^{7}$

Outro pormenor importante na primeira final é o verbo acrediteis. Segundo os manuscritos gregos antigos dos quais dependem a nossa tradução, nós temos duas tradições textuais: uma como o verbo no subjuntivo aoristo (pisteusete) e outra com o verbo no subjuntivo presente (pisteuete). A escolha de uma das formas pode mudar o alcance de nossa compreensão no que diz respeito aos destinatários para os quais os sinais teriam sido escritos. Se o verbo se encontra no aoristo subjuntivo, a tradução poderia ser, se interpretado como aoristo ingressivo: "para que comeceis a acreditar" e indicaria que o objetivo dos sinais seria o de suscitar a fé em Jesus Cristo. Se o verbo, pelo contrário, se encontra no presente subjuntivo, a tradução seria: "para que continueis a acreditar", e indicaria que o relato dos sinais se dirigiria a pessoas já crentes em Jesus, mas que, por algum motivo, necessitam crescer na fé, conservá-la, fortalecê-la. A maioria dos autores, apesar da fragilidade das questões de crítica textual, e baseados ainda em critérios internos sobre a linguagem e teologia do quarto evangelho, optam pelo subjuntivo presente. ${ }^{8}$

A questão de fundo que divide os autores é por que o escopo dos sinais está posto neste lugar do evangelho e não imediatamente após o relato da ressurreição de Lázaro, considerado o último sinal narrado pela maioria dos estudiosos? Para os que sustentam a fonte dos sinais, estes versículos teriam sido sua natural conclusão. ${ }^{9}$ Outros, como Bultmann, por exemplo, defendem que os versículos foram postos aqui para indicarem não uma conclusão dos sinais, mas de todo o evangelho, pois, segundo ele, os termos sinal e palavra são sinônimos na teologia do evangelista. ${ }^{10}$ Como não é objetivo desse artigo

\footnotetext{
${ }^{7}$ SCHNACKENBURG, R., Das Johannesevangelium, p. 150-168; ELOY E SILVA, L. H., Pai, o nome de Deus no Quarto Evangelho, p. 57-63.

${ }^{8}$ BEUTLER, J., Faith and Confession, the Purpose of John, p. 19.

${ }^{9}$ Não será trabalhada nesse artigo a questão relacionada à possível fonte dos sinais e sua redação, tema que poderá ser encontrado, por exemplo, entre outros, em FORTNA, R. T., The Gospel of Signs; BECKER, J., Wunder und Christologie; FORTNA, R. T., The Fourth Gospel and Its Predecessor.

${ }^{10}$ BULTMANN, J., Das Evangelium des Johannes, p. 540-541. Semelhantemente, BOISMARD, M. É.; LAMOUILLE, A., Synopse des Quatre Évangiles en Français, p. 476.
} 
discutir as questões diacrônicas subjacentes ao texto, mas a sua construção em dimensão narrativa e, portanto, sincrônica, consideraremos Jo 20,30-31 como sumário conclusivo de todos os sinais escolhidos pelo evangelista e, por isso mesmo, como sua chave hermenêutica.

Sendo assim, em chave hermenêutica, os sinais, que foram escolhidos pelo evangelista, possuem o claro escopo de fazer com que diante de seu relato, o leitor creia que Jesus é o Cristo, o Filho de Deus e, crendo, tenha a vida em seu nome.

O verbo pisteuein seguido de hoti, "crer que", indica quase sempre a identidade de Jesus, como se pode ver em Jo, 6,69, ele é o Santo de Deus; em Jo 11,27 e 20,31, ele é o Cristo, o Filho de Deus; mas também, sua origem (Jo 11,27; 16,30; 17,8); sua missão como enviado do Pai (Jo 11,42; 17,21); sua unidade com o Pai (Jo 14,10). A preferência do evangelista pelo verbo crer e não pelo substantivo fé parece indicar a dinamicidade do conceito, ${ }^{11}$ já que se espera daquele que crê a confissão e testemunho da fé. ${ }^{12}$ Reconhecer quem Jesus é em suas obras e palavras, crer que ele é o Cristo, o Filho de Deus (dimensão cristológica), é alcançar a vida em seu nome (dimensão soteriológica). Em outras palavras, é parte essencial da natureza do sinal o suscitar a fé em Jesus, o Cristo, Filho de Deus, condição necessária para que em seu nome a vida, a salvação, seja alcançada. ${ }^{13}$

\section{Os sinais em sua dimensão lexical}

O evangelista fala dos muitos sinais e os restringe. Ou seja, ele quis escolher alguns sinais que considerou mais relevantes para a finalidade de seu evangelho. A primeira questão se baseia no significado de quais sejam estes sinais (semeia): são equivalentes a milagres? Se sim, por que o evangelista não usou os termos equivalentes que aparecem nos outros evangelhos?

O termo sinal (semeion) aparece no evangelho 17 vezes: $2,11.18 .23 ; 3,2$; $4,48.54 ; 6,2.14 .26 .30 ; 7,31 ; 9,16 ; 10,41 ; 11,47 ; 12,18.37 ; 20,30$. Nota-se claramente um salto do cap. 12 ao 20. Como se vê claramente, todas as citações, com exceção de 20,30, encontram-se na primeira parte do evangelho, comumente chamada pelos autores de livro dos sinais.

11 ZUMSTEIN, J., Das Johannesevangelium, p. 31-45.

${ }^{12}$ BEUTLER, J., Faith and Confession, the Purpose of John, p. 29.

${ }^{13}$ VAN BELLE, G., Christology and Soteriology in the Fourth Gospel, p. 435-461. 
Em perspectiva narratológica, o termo aparece nas seguintes situações: no contexto das bodas de Caná, onde Jesus transforma a água em vinho, episódio chamado pelo evangelista de primeiro sinal (Jo 2,11); no contexto da cura do filho do funcionário real, chamado pelo evangelista de segundo sinal (Jo 4,48.54); no contexto da multiplicação dos pães (Jo 6,14); no contexto da cura do cego de nascença (Jo 9,16); no contexto da ressurreição de Lázaro (Jo $11,47 ; 12,18)$. As outras entradas do termo referem-se a sinais no plural indicando muito provavelmente os outros muitos sinais que Jesus realizou, mas que não estão escritos no evangelho (Jo 2,23; 3,2; 6,2.26; 7,31; 12,37) como é atestado na última citação do termo no corpo do evangelho (Jo 20,30).

A partir desse elenco, explicitamente mencionados como sinais, em termos lexicais, seriam os seguintes relatos:

1. A mudança da água em vinho nas Bodas de Caná (Jo 2,1-12);

2. A cura do filho do funcionário régio em Caná (Jo 4,46-54);

3. A multiplicação dos pães na Galileia (Jo 6,1-15);

4. A cura do cego de nascença em Jerusalém (Jo 9,1-41);

5. A ressureição de Lázaro em Betânia (Jo 11,1-54).

Nessa perspectiva, a cura do enfermo de Jo 5,1-18 não se enquadraria no elenco dos sinais por não ter sido mencionado como tal? É preciso dar um passo ulterior em nossa análise.

\section{Os sinais em sua dimensão narrativa}

Em termos narrativos, é possível identificar características comuns em todas as perícopes que narram os sinais segundo a perspectiva joanina.

Conforme Aristóteles em sua Poética 1455b, 24-31, o relato de uma tragédia é marcado por dois momentos essenciais, aquele do nó e aquele do desenlace do nó que poderá levar o herói ao sucesso ou ao insucesso. Alguns autores se referirão a esse princípio aristotélico de piramidal incluindo entre o nó e o desenlace a ação transformadora de um estado (nó) ao outro (desenlace). Larivaille, ao analisar contos, percebeu que a transformação realizada pela ação transformadora faz passar de um universo perturbado, como uma falta, um desejo, uma enfermidade, para um universo restabelecido, comumente observável nas narrativas de milagres. ${ }^{14}$

${ }^{14}$ MARGUERAT, D.; BOURQUIN, Y., Para ler as narrativas bíblicas, p. 57-58. 
A transformação leva o sujeito a passar de um estado para o outro, de um nó desencadeado para um desenlace efetuado, gerando plasticamente o seguinte esquema quinário: situação inicial, nó, ação transformadora, desenlace, situação final. ${ }^{15}$

Na situação inicial ou exposição da cena ${ }^{16}$ encontram-se as circunstâncias da ação como indicação espacial (onde?), temporal (quando?) e actancial (quem?). Pode haver a informação de uma necessidade suscitada no ambiente intradiegético, isto é, no interior do relato, e a narrativa pode indicar a tentativa de sua resolução. Na exposição, encontra-se geralmente a apresentação dos personagens que estão em primeiro plano (com verbos no perfeito) e os que estão em segundo plano (com verbos no imperfeito ou particípios com indicação de situação secundária).

Por nó entende-se o elemento que desencadeia o relato, que lhe dá vida, e introduz a tensão narrativa. Também chamado de inciting moment é o momento em que o leitor se depara pela primeira vez com o conflito ou com o problema do relato. ${ }^{17}$ Quase sempre é "o quê" do início de um relato e pode se encontrar na exposição ou confundir-se com o início da ação transformadora. ${ }^{18}$

A ação transformadora, ou complicação na linguagem de Ska, é o processo de alteração da situação da tensão inicial, situado no nível pragmático, cujo foco é a ação, por exemplo a alteração de um estado de enfermidade para um estado de cura, ou no nível cognitivo, cujo foco é a avaliação ou o conhecimento de um elemento até então desconhecido. Em outras palavras, é o momento intermediário que conduz a trama, o episódio ou a cena de seu nó a seu desenlace.

O desenlace ou resolução, também chamado por Ska de clímax ou turning-point, é a liquidação da tensão inicial por meio de uma peripéteia ou de uma anagnórisis ou ainda com a presença de ambas. O desenlace ocorre, em termos narratalógicos, quando o leitor é informado. O desenlace peripeteico ou por peripéteia ocorre quando há uma passagem de um estado para seu oposto, como no caso de um elemento físico, uma enfermidade que é curada,

\footnotetext{
${ }^{15}$ MARGUERAT, D.; BOURQUIN, Y., Para ler as narrativas bíblicas, p. 58.

${ }^{16} \mathrm{O}$ que segue, acerca dos elementos do esquema quinário, encontra-se baseado e em diálogo com MARGUERAT, D.; BOURQUIN, Y., Para ler as narrativas bíblicas, p. 59 e com SKA, J.-L., Sincronia, p. 137-138 e SKA, J.-L., “Our Fathers have told us”, p. 20-21.

${ }^{17}$ SKA, J.-L., Sincronia, p. 137.

${ }^{18}$ SKA, J.-L., "Our Fathers have told us", p. 25.
} 
ou de um estado interior, como no caso da infelicidade que se transforma em felicidade. O desenlace anagnorético ou por anagnórisis ocorre quando há uma passagem da ignorância de algum elemento para o seu conhecimento ou reconhecimento. Nesse caso, a anagnórisis relaciona-se quase sempre com a revelação de um personagem a outro ou ao leitor de sua identidade ou de algo que traz suspense ao relato.

A situação final informa o estado adquirido pelo sujeito depois da ação transformadora cujo ápice é o desenlace do nó inicial. Em termos estruturais conclui a cena, pois o elemento que traz vida àquele relato ou parte dele, o nó, é desfeito.

Os cinco sinais, assim identificados no item anterior desde o ponto de vista lexical, possuem em comum o mesmo esquema quinário.

Em Jo 2,1-12, há uma exposição da cena com os principais elementos (Jo 2,1-2): indicação espacial (Caná da Galileia), indicação temporal (no terceiro dia) e indicação actancial (Jesus e os discípulos no primeiro plano [verbo no perfeito: "Jesus foi convidado e também seus discípulos"] e a mãe de Jesus no segundo plano da cena [verbo no imperfeito: "e a mãe de Jesus estava lá"]). Segue o nó (Jo 2,3), a falta do vinho, claramente vinculado ao seu desenlace (Jo 2,9-11), quando o leitor é informado de que o mestre de cerimônias provou a água transformada em vinho, com a informação da reação diante do desenlace da cena. O nó e o desenlace são intercalados pela ação transformadora (Jo 2,4-8). Enfim, a cena se conclui com a informação de que Jesus, sua mãe, irmãos e discípulos desceram para Cafarnaum (Jo 2,12). Além do desenlace peripeteico, a situação inicial da ausência de vinho que é transformada pela presença de vinho no final, há o desenlace anagnorético: a manifestação da glória de Jesus e o discípulos que nele creem (Jo 2,9-11).

Em Jo 4,46-54, encontram-se, também, os principais elementos da exposição da cena (Jo 4,46-47): indicação espacial (Caná da Galileia), indicação temporal (no terceiro dia, segundo a informação cronológica de Jo 4,40.43), indicação actancial (Jesus e o funcionário real). ${ }^{19}$ Segue o nó (Jo 4,47), o filho que está à morte seguido do pedido do pai $(\mathrm{Jo} 4,49),{ }^{20}$ vinculado ao seu desen-

\footnotetext{
${ }^{19} \mathrm{O}$ filho, os servos e todos os da sua casa (Jo 4, 51.53) estão no relato, mas não na cena em que Jesus se encontra com o funcionário real. Por isso, não são aqui considerados como elemento actancial.

${ }^{20}$ Elemento muito semelhante ao primeiro sinal ocorrido em Caná, em que após a indicação do nó aparece o pedido da mãe (Jo 2,3).
} 
lace (Jo 4,51-53), quando o leitor é informado de que o filho do funcionário real vivia e que a transformação de seu quadro febril tinha se dado à hora sétima, precisamente a hora em que Jesus lhe dissera "teu filho vive". Não existe propriamente um relato da ação transformadora. Em termos narrativos, ela foi imediata, pois não foi narrado seu processo como no primeiro sinal. A cena se conclui, relatando, como no primeiro sinal, o movimento de Jesus que se desloca de um lugar para outro (Jo 4,54). Também aqui, além do desenlace peripeteico, em que o estado do filho que estava à morte é superado pela palavra de Jesus que lhe possibilita viver, há o desenlace anagnorético: o funcionário real e toda sua família creem (Jo 4,53).

Em Jo 6,1-15, deparamo-nos mais uma vez com os principais elementos da exposição da cena (Jo 6,1-4): indicação espacial (outra margem do mar da Galileia ou de Tiberíades), indicação temporal (estava próxima a Páscoa) e indicação actancial (Jesus e os discípulos no primeiro plano e a grande multidão no segundo plano). O nó é a falta do pão (Jo 6,5-7), vinculado ao seu desenlace (Jo 6,11b-14) em que o leitor é informado de que todos se saciaram e de que ainda sobraram pedaços que encheram doze cestos. A ação transformadora é relatada nos versículos 8-11a. O desenlace é peripeteico, pois houve uma mudança de uma situação de carência inicial do pão para sua presença no final da cena, mas há, ainda, um desenlace anagnorético, não com a informação explícita de que creram após o sinal, mas com o seu equivalente presente na confissão "esse é, verdadeiramente, o profeta que deve vir ao mundo" (Jo 6,14), pois há um reconhecimento do protagonista da cena. ${ }^{21}$

Em Jo 9,1-41, temos um relato composto por várias cenas, no sentido de que entram e saem personagens, mas a exposição da cena (Jo 9,1-2a), elemento significativo para a compreensão do escopo do relato, possui as seguintes informações: indicação espacial (em Jerusalém, pois Jesus sai do templo e vê o cego; não há indicativo espacial que determine o local exato [Jo 8,59]), indicação temporal (não é clara, mas deve ser posta como posterior à discussão que Jesus teve com os judeus sobre sua identidade e relação com a figura de Abraão [Jo 8,33-59]), indicação actancial (Jesus, os discípulos e o cego). O nó, elemento que dá vida e sentido ao texto, não é somente a cegueira, mas a relação que ela possui com a manifestação das obras de Deus (Jo 9,2b-3). O desenlace da cegueira, que se dá por peripeteia, ocorre logo em Jo $9,7 \mathrm{~b}$, quan-

${ }^{21}$ SKA, J.-L., "Our Fathers have told us", p. 27. 
do o cego passa a ver. Há uma ação transformadora que ocorre nos versículos 6 a 7a, onde se narra o processo que o leva após ter recebido a lama sobre os olhos, feita com a saliva de Jesus, a ir lavar-se na piscina de Siloé, lavar-se e voltar vendo claro. Seguem diálogos sucessivos do cego com os vizinhos em que ele narra que foi curado por Jesus, mas não sabe onde Jesus está (Jo 9,812); do que fora cego com os fariseus que, ao ser questionado por eles de que não poderia ter sido curado em dia de sábado e que Jesus seria, por isso, um pecador, responde que Jesus era um profeta (Jo 9,13-17); dos judeus com os pais do que fora cego, que por medo, dizem apenas que o filho nasceu cego, mas não sabem como está vendo ou quem lhe abriu os olhos (Jo 9,18-23); dos judeus com o que fora cego que o questionam mais uma vez por não saberem de onde Jesus é e por ele ter desrespeitado o sábado, não aceitando as respostas do que fora cego por considerarem-no nascido em pecado (Jo 9,24-34); enfim, de Jesus com o que fora cego quando ocorre o desenlace por anagnórisis (Jo 9,35b-38a) e há a confissão de fé do que fora cego: “creio, Senhor!” o qual se prostra diante de Jesus. A conclusão da cena não segue os parâmetros comuns semelhantes ao relato dos outros sinais, pois ecos da interlocução de Jesus com seus opositores continuarão na alegoria do Bom Pastor, como se pode perceber em Jo $10,21 .^{22}$

Em Jo 11,1-54, temos igualmente um relato composto por várias cenas. A exposição da cena do relato onde o leitor é informado do suposto inciting moment, a doença de Lázaro, não diz respeito à indicação espacial onde o turning-point ocorrerá. Com efeito, Jesus não estava na Judeia (Jo 11,7), quando ficou sabendo do estado de saúde do amigo a quem amava (Jo 11,5). O nó não pode ser a doença de Lázaro, mas sua morte, o real inciting moment da narração, como informado no versículo 14, pois este será o elemento que dará vida ao relato. Ao nó relaciona-se diretamente por peripeteia o desenlace a ocorrer no versículo 44, quando o leitor é informado de que Lázaro tornou a viver. Há também a presença da anagnórisis com a informação de que muitos dos judeus que tinham ido à casa de Maria, tendo visto o sinal que Jesus fizera, creram nele (Jo 11,45). A conclusão do relato se dará no versículo 54, quando Jesus retira-se para a região próxima do deserto, para a cidade chamada Efraim, juntamente com seus discípulos.

Diante de alguns componentes comuns que percorreram os cinco sinais, assim identificados pela presença lexical do termo semeion e, agora,

${ }^{22}$ DU RAND, J. A., A Syntactical and narratological reading of John 10 in coherence with chapter 9, p. 94-115. 
com os passos da análise narrativa, enquanto indicador de elementos estruturantes desses relatos, podemos também incluir o texto de Jo 5,1-18, pois mesmo que nele não apareça o termo sinal ou algum equivalente, podemos identificar os componentes comuns que estruturaram os outros sinais acima analisados.

Com efeito, na exposição da cena é posto um quadro típico do relato de milagres, chamado particularmente pelo quarto evangelista de sinal, por suscitar a fé em Jesus Cristo, o Filho de Deus. Inicia-se no versículo $1 \mathrm{com}$ uma indicação temporal (uma festa dos judeus) e espacial (Jerusalém, mais particularmente junto à piscina de Betzata), seguida da indicação actancial (em segundo plano numerosos doentes, cegos, coxos e paralíticos [Jo 5,3] e o homem que estava doente havia trinta e oito anos [Jo 5,4], o qual Jesus traz para o primeiro plano da cena ao dirigir-lhe a palavra: "queres ficar curado?" no versículo 6. Em Jo 5,7 o enfermo fala da dificuldade de entrar na piscina para ser curado e nos versículos 8-9 o leitor é informado de que, pela palavra de Jesus, o homem ficou curado, tomou o seu leito e pôs-se a andar. A cena poderia ter terminado aqui com o desenlace claramente peripeteico, se não fosse posto um segundo inciting moment à cena com a informação de que Jesus havia curado o homem em um dia de sábado (Jo 5,9b). Esta informação leva os judeus a perseguirem Jesus $($ Jo 5,16$)$ e a procurarem matá-lo, pois, além de violar o sábado, se referia a Deus como Pai, fazendo-se igual a Deus (Jo 5,18). Não há, diversamente dos outros sinais a indicação da manifestação da fé, mas, pelo contrário, a sua recusa, o que não nos tira do mesmo campo semântico. ${ }^{23}$

\section{Os sinais em sua dimensão semântico-teológica}

Além da presença dos elementos narrativos, acima identificados, podemos dizer que os seis sinais estão em relação de inclusão concêntrica, pelos aspectos semânticos e temáticos que aí se encontram.

O primeiro sinal e o último possuem, no início do relato, a intervenção de uma figura feminina que informa Jesus de uma necessidade que será o motivo da realização da ação transformadora. Em Caná da Galileia, a mãe de Jesus informa Jesus que o vinho tinha acabado (Jo 2,3) e, no relato sobre a ressurreição de Lázaro, as duas irmãs mandam informar Jesus que

${ }^{23}$ EGGER, W., Methodenlehre zum Neuen Testament, p. 100. 
aquele a quem ele amava estava doente (Jo 11,3). Se não bastasse isso, enquanto em Jo 2,1-12 celebra-se o início da vida em família, por meio da celebração de um matrimônio, em Jo 11,1-54, o leitor depara-se com a experiência da doença e da morte em uma família. Após o primeiro sinal, há uma referência à destruição do templo (Jo 2,19-21) e ao mistério pascal de Cristo, sua ressurreição (Jo 2,22), o que também pode ser claramente percebido após o último sinal com a menção à destruição do lugar santo (Jo 11,48) e ao mistério pascal de Cristo, sua sepultura, no episódio sucessivo ainda em Betânia, da unção dos pés de Jesus por Maria, irmã de Lázaro (Jo 12,7).

O segundo sinal e o quinto também possuem paralelos semânticos e temáticos. No início do relato do segundo sinal, o funcionário real se volta para Jesus e pede-lhe que cure seu filho que está à morte. Diante da intervenção, Jesus dá um breve ensinamento em tom de admoestação: "Se não virdes sinais e prodígios, não crereis" (Jo 4,48). Segue o imperativo: "vai, teu filho vive" (Jo 4,50). Na conclusão do relato, o leitor é informado de que o pai creu e todos os de sua casa, o que equivale a compreender que também o filho curado começou a crer (Jo 4,53). No início do relato do quinto sinal, os discípulos de Jesus lhe perguntam sobre quem pecou para que o homem nascesse cego (Jo 9,2). Em resposta, Jesus, primeiro em tom de ensinamento, diz que não foi pelo pecado que nasceu cego, mas para que se manifestem naquele homem as obras de Deus (Jo 9,3) e, depois, em tom de admoestação, recorda que quando vem a noite ninguém pode trabalhar (Jo 9,4b). Segue o imperativo: "vai lavar-te na piscina de Siloé" (Jo 9,7a). Na conclusão do relato, o leitor depara-se com a confissão de fé do que foi curado (Jo 9,35-38), mas o mesmo não acontece com seus pais (Jo 9,22), prováveis representantes do grupo de cripto-cristãos da comunidade joanina, que creram em Jesus, mas não confessaram sua fé publicamente, por medo de serem expulsos da sinagoga. ${ }^{24}$ Dentro do quadrilátero semântico, a oposição entre a confissão da fé e sua recusa encontram-se perfeitamente em relação. ${ }^{25}$ Significativo perceber que em ambos os sinais, há a cura de um filho.

O terceiro sinal e o quarto também possuem paralelos semânticos e temáticos. São os únicos sinais em que a iniciativa é de Jesus, no sentido

\footnotetext{
${ }^{24}$ BROWN, R. E., A Comunidade do Discípulo Amado, p. 74-76.

${ }^{25}$ EGGER, W., Methodenlehre zum Neuen Testament, p. 100.
} 
de que ela não é suscitada por algum de seus interlocutores intradiegéticos e nem é uma resposta a uma pergunta de algum deles. No caso do enfermo da piscina probática, Jesus o vê deitado e, sabendo que estava assim, havia muito tempo, pergunta-lhe se queria ficar curado (Jo 5,6). Diante da pergunta de Jesus, segue uma resposta em tom de empecilho. Segundo o enfermo, ele não tem quem o ajude a entrar na piscina para ficar curado (Jo 5,7). Jesus então lhe diz, por meio de um imperativo: "levanta-te, toma teu leito e anda" (Jo 5,8). Não há a manifestação da fé, mas há uma menção importante ao título cristológico de Jesus como "o Filho de Deus" (Jo $5,18)$. O relato ocorre ao lado de uma piscina. No caso da multiplicação dos pães, é Jesus quem também vê a situação de necessidade e pergunta a Filipe: "onde conseguiremos pão para eles comerem?" (Jo 6,5). O evangelista, no entanto, informa ao leitor que Jesus já sabia o que faria $\left(J_{0} 6,6\right)$. Como no sinal anterior, após a pergunta de Jesus, segue uma resposta de Filipe em tom de empecilho: "Nem duzentos denários de pão bastariam, para dar um pouquinho a cada um" (Jo 6,7), corroborada pela fala de André que informa a presença de um menino com cinco pães de cevada e dois peixes, o que ele considera insuficiente para tanta gente (Jo 6,8-9). Jesus intervém também por meio de um imperativo: "fazei-os sentar-se" (Jo 6,10) e, depois, "juntai os pedaços que sobraram, para que nada se perca" (Jo 6,12). Também aqui não há a presença do verbo "crer" o que poderia indicar a manifestação explícita da fé em Jesus, mas há uma menção importante ao título cristológico de Jesus como "o profeta que deve vir ao mundo" (Jo 6,14). O relato ocorre à margem do mar da Galileia. Há, portanto, também uma alusão à presença da água.

Após termos percorrido esse esquema estruturalmente concêntrico, cabe-nos recordar que é parte essencial do sinal, segundo Jo 20,30-31, a dupla dimensão cristológica e soteriológica. Em todos os seis sinais, nota-se a presença de ambas: 


\begin{tabular}{|c|c|c|}
\hline & Dimensão cristológica & Dimensão soteriológica \\
\hline Jo $2,1-12$ & "manifestou a sua glória" (v.11a) & $\begin{array}{c}\text { "seus discípulos creram nele" } \\
\text { (v.11b) }\end{array}$ \\
\hline Jo $4,46-54$ & “Senhor" (v.49) ${ }^{1}$ & $\begin{array}{l}\text { "creu ele e toda a sua família" } \\
\text { (v.53b) }\end{array}$ \\
\hline Jo $5,1-18$ & $\begin{array}{l}\text { "dizia que Deus era seu Pai" (v.18) } \\
\text { "o Filho" }(5,19.20 .21 \cdot 22 \cdot 23 \cdot 25.26)^{2}\end{array}$ & $\begin{array}{c}\text { "como crereis nas minhas } \\
\text { palavras?" }(6,47)\end{array}$ \\
\hline Jo $6,1-15$ & $\begin{array}{l}\text { "o profeta que deve vir ao mundo" } \\
\text { (v.14) } \\
\text { "Tu és o Santo de Deus" }(6,69)^{3}\end{array}$ & "nós cremos..." $(6,69)$ \\
\hline Jo $9,1-41$ & $\begin{array}{l}\text { "é um profeta" (v.17); "Filho do } \\
\text { Homem" (v.35); "Senhor" (v.38) }\end{array}$ & "eu creio" (v.38a) \\
\hline Jo $11,1-54$ & $\begin{array}{l}\text { "Filho de Deus" (v.4); "o Cristo, } \\
\text { Filho de Deus" (v. 27b) }\end{array}$ & $\begin{array}{c}\text { "eu creio firmemente" (v.27a) } \\
\text { "muitos judeus creram nele" } \\
\text { (v.45b) }\end{array}$ \\
\hline
\end{tabular}

A identificação da dupla dimensão corrobora a compreensão de que os relatos foram construídos em função do escopo que o sinal representa. Os sinais revelam quem é Jesus, não somente para as personagens das cenas que em nível intradiegético encontram-se com Jesus e presenciam a força de sua palavra e de seus gestos que transformam a vida das pessoas pela sua presença, mas também para o leitor. O leitor que, de uma forma privilegiada, acompanha a revelação da identidade de Jesus pelo relato dos sinais e a manifestação da fé em sua pessoa ou não, como acontece no contexto de Jo 5,1-47.

Da abertura ao que o sinal representa e indica depende também a compreensão de seu horizonte soteriológico. Com efeito, como expressa claramente o evangelista, é preciso crer para que se alcance a vida no nome de Jesus,

\footnotetext{
${ }^{26}$ BROWN, R. E., The Gospel According to John I-XII, p. 191.

${ }^{27}$ Sobre o discurso que sucede ao sinal e amplia o seu significado, veja: DODD, C. H., The Interpretation of the Fourth Gospel, p. 142.

${ }^{28}$ No caso do cap. 6, após o sinal, há um grande discurso na sinagoga de Cafarnaum em que o pão da multiplicação dos pães torna-se motivo para que Jesus fale do maná no deserto e do pão que é o corpo dele mesmo a ser doado para a vida do mundo $(6,51)$. A confissão de fé, posta na boca de Pedro, será retardada em função do discurso que segue o sinal, estrutura já percebida por DODD, C. H., The Interpretation of the Fourth Gospel, p. 142.

${ }^{29}$ Há uma progressão no que diz respeito à compreensão da identidade de Jesus, cujo título cristológico ápice é o de Senhor, seguido pelo gesto de prostração do que fora cego. Alguns autores retêm o uso do título Senhor aqui associado ao prostrar-se a um acréscimo de tom litúrgico: THYEN, H., Das Johannesevangelium, p. 473.
} 
o Cristo, Filho de Deus (Jo 20,30-31). Como o evangelista recordará, apesar de Jesus ter realizado tantos sinais diante de seus interlocutores, nem todos creram nele (Jo 12,37). Em outras palavras, os sinais realizados não lograram seu escopo cristológico e soteriológico, não porque não foram eficazes, mas porque não suscitaram em todos a abertura ao seu significado. Neste sentido, mesmo não havendo o termo semeion no contexto de Jo 5,1-47 e não tendo sido relatada a manifestação positiva do crer em Jesus, mas o seu contrário, retemos que este texto tenha uma função pragmática de alta relevância justamente por manifestar o lado contrário dos que não aceitaram o sinal de Jesus. Esta dimensão se fará de alguma forma presente na reação dos interlocutores de Jesus, além de Jo 5,19-47; em Jo 6, 22-71; Jo 9,13-34.40-41; Jo 11,47-53. Tal reação sinaliza, no contexto dos sinais, a estreita relação que eles possuem com o mistério da hora de Jesus, de sua paixão, morte e ressurreição, elemento esse mencionado já no primeiro sinal: “o que há entre mim e ti, ó mulher? A minha hora ainda não chegou” (Jo 2,4).

\section{Conclusão}

Aparentemente a discussão sobre o número dos sinais pode parecer desnecessária, pois em termos teológicos não parece mudar o sentido pelo qual foram escolhidos pelo autor do quarto evangelho, qual catálogo das obras realizadas por Jesus, cujo escopo seria o de revelar sua identidade e manifestar sua dimensão salvadora.

No entanto, pareceu-nos pertinente levantar mais uma vez a discussão, em função de uma dupla questão relacionada ao gênero literário "sinal" e a seu sentido simbólico-teológico.

Enquanto os sinóticos se referem a feitos taumatúrgicos de Jesus chamando-os de milagres, o quarto evangelho os chama de sinais. Mesmo que alguns autores retenham que se trate simplesmente de uma escolha terminológica, não somos de acordo, pois há claramente uma diferença no que diz respeito a uma característica fundamental do gênero literário. Enquanto que, para que um milagre ocorra, espera-se a manifestação da fé, narrada em quase todos os casos desses relatos, o sinal diversamente não necessita da manifestação prévia da fé, mas tem justamente o escopo de suscitá-la (Jo 2,11). Com efeito, em muitos relatos de milagres nos sinóticos ou há a manifestação prévia da fé do que será miraculado ("se queres, tens o poder de purificar-me" [Mc 1,40]) ou alguém pede em seu nome ("trouxeram-lhe todos os que estavam enfermos e 
endemoninhados" [Mc 1,32]). Há, ainda, a iniciativa de Jesus, nos sinóticos, o que se aproxima muito do gênero literário sinal, presente no quarto evangelho, quando após o feito de Jesus, há a manifestação da fé ou contra ela (Mc 3,1-6).

Nesse sentido, a travessia do mar em Jo 6,16-21, não pode ser enquadrada no gênero literário sinal. Primeiramente, não possui o elemento lexical semeion. Depois, embora siga também nos sinóticos ao episódio da multiplicação dos pães, não possui aqui as características, por exemplo, presentes em Mt 14,22-33 do vento contrário e do vento que cessa pela palavra de Jesus, indicando uma ação transformadora. Em Jo 6,16-21, não há a ação transformadora do vento contrário que é amainado. Pelo contrário, narra-se que Jesus ao entrar no barco, esse chegou imediatamente à terra para a qual se dirigiam. Enfim, em termos semânticos e teológicos não há uma revelação cristológica, nem a manifestação da fé (dimensão soteriológica).

Em termos simbólicos, é preciso dizer que o número seis exerce um papel significativo no corpo do quarto evangelho. No primeiro sinal, há a presença de seis talhas de pedra (Jo 2,6); Jesus se encontra com a samaritana à hora sexta (Jo 4,6b); Jesus vai a Betânia, seis dias antes da Páscoa (Jo 12,1); Jesus é posto à cruz à hora sexta (Jo 19,14). Coincidentemente ou não, todas essas citações vinculam-se ao mistério da hora de Jesus, de sua paixão, morte e ressurreição. No primeiro sinal, há a menção à hora de Jesus que ainda não havia chegado, mas, mesmo assim, ele realiza o sinal, manifesta sua glória e seus discípulos creem nele. $\mathrm{O}$ encontro de Jesus com a samaritana ocorre à hora sexta, mesma hora em que Jesus será posto à cruz, segundo a tradição joanina, já que segundo Marcos ele foi pregado à cruz à hora terceira (Mc 15,25). $\mathrm{O}$ motivo que suscitará o diálogo entre Jesus e a mulher é o tema da sede (Jo $4,7)$, tema que se repetirá também na cruz, quando ele dirá: "tenho sede" (Jo 19,28). Semelhantemente, a última visita que Jesus faz a seus amados amigos, Marta, Maria e Lázaro antes de sua Páscoa, seis dias antes, vincula o gesto de Maria que unge seus pés com perfume de nardo puro à sepultura de Jesus (Jo 12,7). Enfim, a última menção ao número seis dá-se justamente no momento ápice da "hora de Jesus" em que sobre a cruz ele se revela como o cordeiro pascal, pois é crucificado à hora sexta, à véspera da Páscoa, dia e hora em que os cordeiros pascais eram sacrificados no templo. ${ }^{30}$

Nessa perspectiva, a dimensão cristológica e soteriológica dos sinais encontram na hora de Jesus sua mais perfeita realização, pois ali ele se revela

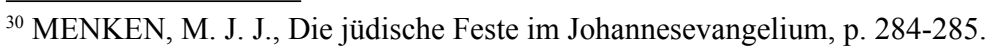


plenamente como o Cristo, o salvador e talvez, propriamente por isso, de forma sutil tenha o evangelista se referido a este momento com o verbo semaino (Jo 12,33; 18,32), do mesmo campo semântico de semeion, para recordar ao leitor a ligação entre os sinais e a hora sexta, a hora de Jesus, a hora de seu retorno ao Pai, a hora de sua elevação (Jo 12,32-33), "a fim de que todo o que nele (dimensão cristológica) crer, tenha a vida eterna (dimensão soteriológica [Jo 3,14b-15]).

\section{Referências bibliográficas}

BEASLEY-MURRAY, G. R. John. Waco / Texas: Word, 1987.

BECKER, J. Wunder und Christologie: zum literarkritischen und christologischen Problem der Wunder im Johannesevangelium. NTS 16, p. 130-148, 1970.

BETZ, O. Jesus: Der Messias Israels. Aufsätze zur biblischen Theologie. Tübingen: Mohr-Siebeck, 1987.

BEUTLER, J. Faith and Confession, the Purpose of John. In: PAINTER, J.; CULPEPPER; R. A.; SEGOVIA, F. F. (Eds.). Word, Theology, and Community in John. Saint Louis: Chalice Press, 2002. p. 19-31.

BOISMARD, M. É.; LAMOUILLE, A. Synopse des Quatre Évangiles en Français. L'Évangile de Jean. Paris: Cerf, 1977. v.3.

BROWN, R. E. A Comunidade do Discípulo Amado. São Paulo: Paulinas, 1999.

BROWN, R. E. An Introduction to the Gospel of John. New York / London / Toronto / Sydney / Auckland: Doubleday, 2004.

BROWN, R. E. The Gospel According to John I-XII. New York: Doubleday, 1966.

BULTMANN, J. Das Evangelium des Johannes. Göttingen: Vandenhoeck und Ruprecht, 1968.

BUltMAnN, R. Theologie des Neuen Testaments. Tübingen: J.C.B Mohr (Paul Siebeck), 1965.

CARSON, D. A. The Gospel According to John. Grand Rapids: Eerdmans, 1991. 
DODD, C. H. The Interpretation of the Fourth Gospel. Cambridge: Cambridge University Press, 1953.

DU RAND, J. A. A Syntactical and narratological reading of John 10 in coherence with chapter 9. In: BEUTLER, J; FORTNA, R. T. (Ed.). The Shepherd Discourse of John 10 and its Context. Cambridge: Cambridge University Press, 1991. p. 94-115.

EGGER, W. Methodenlehre zum Neuen Testament: Einführung in linguistische und historisch-kritische Methoden. Leipzig: Saint Benno-Verlag, 1989. ELOY E SILVA, L. H. Pai, o nome de Deus no Quarto Evangelho. II CONGRESSO DA ANPTECRE, 2009, Belo Horizonte. Fenomenologia e hermenêutica do religioso - Anais com textos completos, 2009. p. 53-64.

FORTNA, R. T. The Fourth Gospel and Its Predecessor. Edinburgh: T\&T Clark, 1988.

FORTNA, R. T. The Gospel of Signs: A Reconstruction of the Narrative Source Underlying the Fourth Gospel. Cambridge: Cambridge University Press, 1970.

ISER, W. Der Implizite Leser: Kommunikationsformen des Romans von Bunyan bis Beckett. München: Wilhelm Fink Verlag, 1972.

MARGUERAT, D.; BOURQUIN, Y. Para ler as narrativas bíblicas: Iniciação à análise narrativa. São Paulo: Loyola,2009.

MENKEN, M. J. J. Die jüdische Feste im Johannesevangelium. In: LABAHN, M.; SCHOLTISSEK, K.; STROTMANN, A. Israel und seine Heilstraditionen im Johannesevangelium. Festgabe für Johannes Beutler SJ zum 70. Geburtstag / Paderborn / München / Wien / Zurich: Ferdinand Schöningh, 2004. p. 269-286.

MORRIS, L. Jesus is the Christ: Studies in the Theology of John. Grand Rapids: Eerdmans, 1989.

NICOL, W. The Semeia in the Fourth Gospel: Tradition and Redaction. Leiden: Brill, 1972.

SANDERS, J. N. A Commentary on the Gospel According to St. John. London: Adam \& Charles Black, 1968.

SCHNACKENBURG, R. Das Johannesevangelium. Freiburg: Herder, 1971.v.2 (Kommentar zu Kap. 5-12). 
SKA, J.-L. "Our Fathers have told us": Introduction to the Analysis of Hebrew Narratives. Roma: Pontificio Istituto Biblico, 1990.

SKA, J.-L. Sincronia: a análise narrativa. In: SIMIAN-YOFRE, H. (Coord.). Metodologia do Antigo Testamento. São Paulo: Loyola, 2000. p. 123-148.

SMALLEY, S. S. John: Evangelist and Interpreter: History and Interpretation in the Fourth Gospel. Greenwood, S.C.: Attic Press, 1978.

THÜSING, W. Die Erhöhung und Verherrlichung Jesu im Johannesevangelium. Münster: W. Aschendorff, 1979.

THYEN, H. Das Johannesevangelium. Tübingen: Mohr Siebeck, 2005.

VAN BELLE, G. Christology and Soteriology in the Fourth Gospel. The Conclusion to the Gospel of John revisited. In: VAN BELLE, G.; VAN DER WATT, J. G.; MARITZ, P. (Eds.). Theology and Christology in the Fourth Gospel: Essays by the Members of the SNTS Johannine Writings Seminar. Leuven: Leuven University Press, 2005. p. 435-461.

ZUMSTEIN, J. Das Johannesevangelium: Eine Strategie des Glaubens. In: ZUMSTEIN, J. Kreative Erinnerung. Relecture und Auslegung im Johannesevangelium. Zürich: Theologischer Verlag, 1999. p. 31-45.

Luís Henrique Eloy e Silva Doutor em Ciência Bíblica pelo Pontifício Instituto Bíblico de Roma Docente de Sagrada Escritura na Pontifícia Universidade Católica de

Minas Gerais e na Faculdade Jesuíta de Belo Horizonte Belo Horizonte / MG - Brasil E-mail: luishenrique@pucminas.br

Recebido em: 25/09/19

Aprovado em: 11/10/19 